\title{
BITEMPORAL DEPRESSION OF THE VISUAL FIELDS DUE TO AN OCULAR CAUSE*
}

\author{
BY \\ HENRY BERRY \\ The National Hospital, Queen Square, London
}

BITEMPORAL depression of the visual fields is diagnostic of chiasmal interference. More rarely, demyelination involving the body of the chiasma, or abnormalities of the optic disc or adjacent retina may be responsible. It is with the latter group that this paper is concerned.

\section{Case Report}

A 48-year-old housewife attended an optician because of occasional pain in the right temple, was found to have a bitemporal field defect, and was referred to Moorfields' Eye Hospital, and was subsequently seen in the Physician's Clinic. She had worn glasses for myopia since the age of 6 , had suffered from an erythema nodosum-like illness in childhood, and had undergone a hysterectomy for fibroids 9 years previously, but had otherwise been symptom-free. She first attended Moorfields on September 7, 1961.

Examination.- The visual acuity was $6 / 9$, with $-8 \mathrm{D}$ sph., $-2 \mathrm{D}$ cyl., axis $30^{\circ}$, in the right eye, and $6 / 6$ with $-6.25 \mathrm{D}$ sph., $-0.75 \mathrm{D}$ cyl., axis $15^{\circ}$ in the left. The optic discs (Fig. 1, overleaf) were tilted downwards, with inferior crescents bilaterally and the vessels entering and leaving the disc at its upper edge.

The peripheral visual fields (Fig. 2A, overleaf), tested without correction, were relatively full to $10 / 330 \mathrm{~W}$, with perhaps a mild depression at the extreme periphery to $1 / 330$ W. There was a bitemporal depression of the central field (Fig. 2B, overleaf), most marked in the upper quadrants and extending across the midline, less marked in the lower quadrants, and failing to reach the midline there. The depression was of a relative type, involved targets of $3 / 2000$ to $7 / 2000 \mathrm{~W}$, and extended into the intermediate field to about $40^{\circ}$ from fixation, and was more extensive on the left.

Neurological and general examinations were within normal limits, and skull $x$ rays were normal.

Treatment. - The headaches improved with mild analgesics, and follow-up examinations of the visual fields, last performed on May 16, 1962, have revealed no change.

\section{Comment}

Defects in the visual fields due to anomalies of the optic disc and the adjacent retina have been noted by several authors. Traquair (1957) stated that paracaecal disturbances might occur in association with myopia. Dubois-Poulsen (1952) described temporal paracentral depression in myopia.

* Received for publication November 1, 1962. 

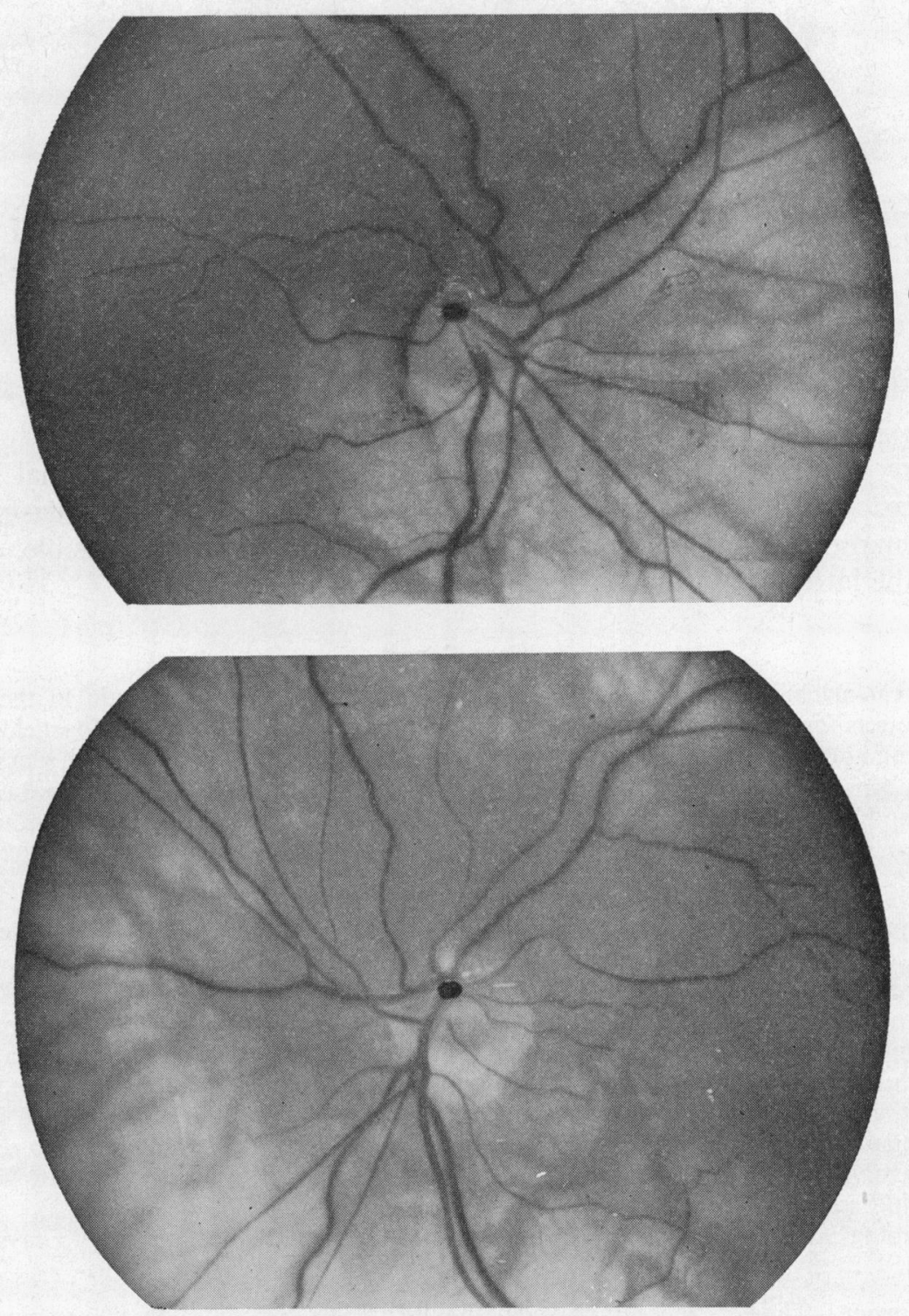

Fig. 1.-Fundi. (A) Right. (B) Left.

(A) 


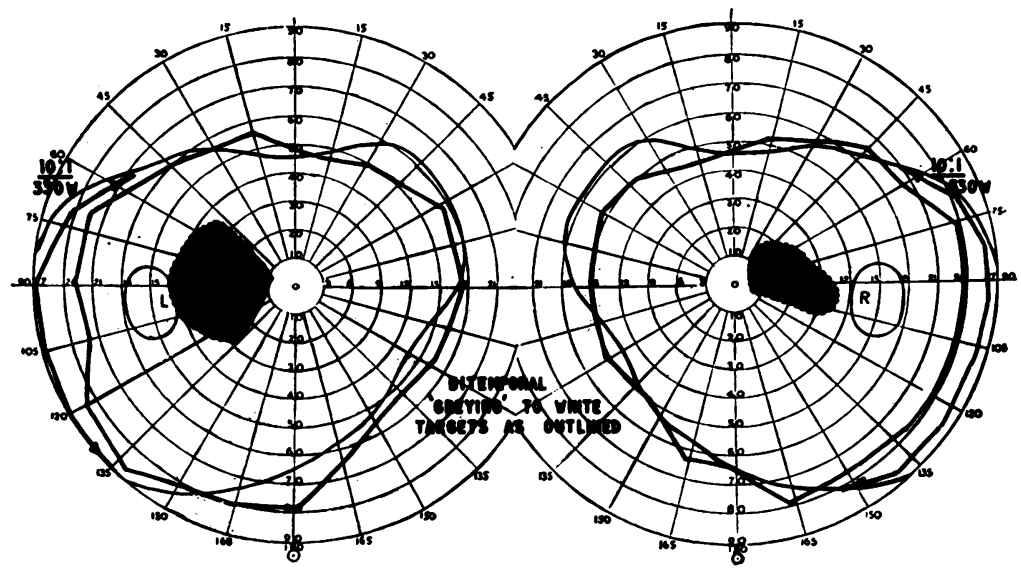

Fig. 2A.-Intermediate and peripheral fields. The central depression extends into the intermediate field to about $40^{\circ}$ from fixation as an area of "greying", and is more extensive in the left field. The periphery is full to $10 / 330 \mathrm{~W}$, and there is possibly a mild depression at the extreme periphery to $1 / 330 \mathrm{~W}$.
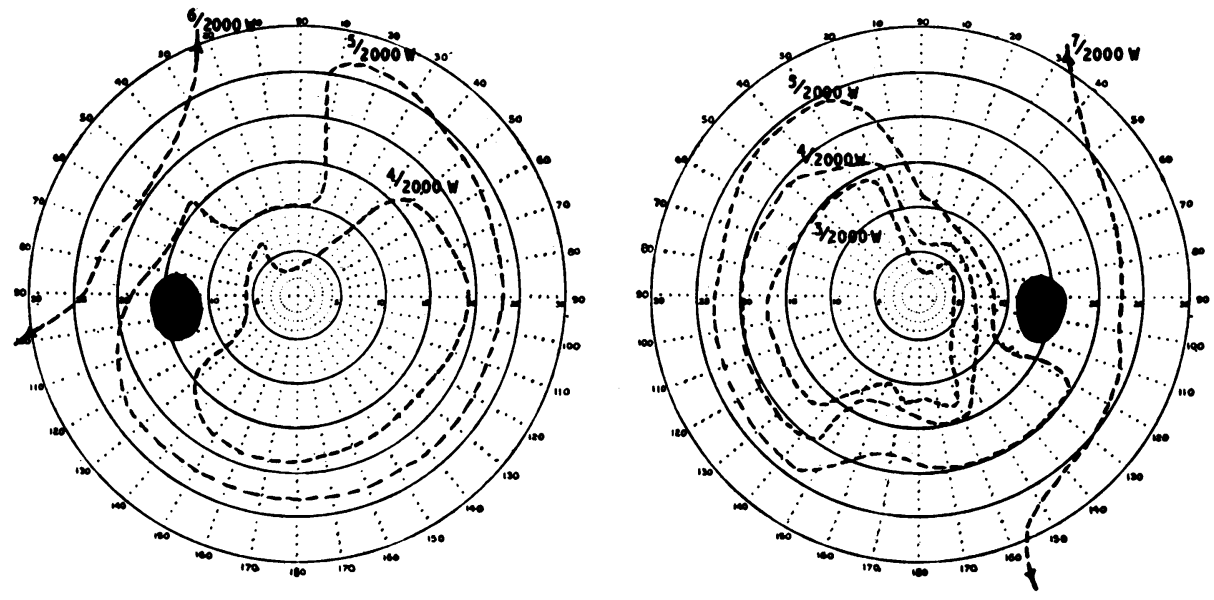

FIG. 2B.-Central fields, charted without correction, reveal bitemporal depression, greatest in the upper quadrant, without alignment along the vertical meridian, and of greater intensity in the left eye.

When charted with correction (not illustrated), the $1 / 2000 \mathrm{~W}$ and $2 / 2000 \mathrm{~W}$ isopters corresponded approximately with $3 / 2000 \mathrm{~W}, 4 / 2000 \mathrm{~W}$, and $5 / 2000 \mathrm{~W}$ respectively. The isopter to $15 / 2000$ $R$ corresponded approximately to $4 / 2000 \mathrm{~W}$ on the left, and to $3 / 2000 \mathrm{~W}$ on the right.

The patient reported here displays a defect that is similar to several of those noted by Rucker. The field defect appears to be due to the congenital anomaly of the optic discs and the associated choroidal thinning. Although superficial assessment could raise the question of chiasmal compression, the presence of myopic astigmatism, the tilted appearance of the optic discs, the 
bitemporal depression of a characteristic type, with a normal sella, and absence of progression on serial examinations, would all lead to a firm diagnosis. In particular, the absence of alignment of the depressed isopters along a vertical meridian, and the absence of a hemianopic character to the field for red, would on their own merits, virtually exclude chiasmal interference.

\section{Summary}

An example of bitemporal depression involving the central and intermediate visual fields, of a distinctive character, and associated with a congenital anomaly, choroidal thinning, and astigmatic myopia, is described.

The author is grateful to Dr. C. J. Earl for permission to publish this case, and for aid and advice during its preparation, and to Mr. S. J. H. Miller for helpful advice and criticism.

\section{REFERENCES}

Dubois-Poulsen, A. (1952). “Le champ visuel”, pp. 584-594. Masson, Paris.

RUCKER, C. W. (1946). Arch. Ophthal. (Chicago), 35, 546.

TraquaIR, H. M. (1957). "An Introduction to Clinical Perimetry", 7th ed., ed. G. I. Scott, p. 105. Kimpton, London.

ZIERING, J. (1936). Klin. Mbl. Augenheilk., 97, 169. 